\title{
PRAGMATIC COMPETENCE OF THE YEMENI EFL LEARNERS
}

\author{
Ahmed Qasem H. Al-Khadhmi ${ }^{1 \mathrm{i}}$, \\ Mirza M. B. ${ }^{2}$, \\ Abdullah Ali Al-Eryani ${ }^{3}$ \\ ${ }^{1}$ Research Scholar, \\ School of Languages, Literature \& Cultural Studies, \\ People's College, \\ Nanded, India \\ ${ }^{2}$ Associate Professor, Research Supervisor, \\ School of Languages, Literature \& Cultural Studies, \\ People's College, \\ Nanded, India \\ ${ }^{3}$ Assistant Professor, \\ Applied Linguistics, \\ Department of English language, \\ Education Faculty, \\ Thamar, Yemen
}

\begin{abstract}
:
The present study aimed at investigating the pragmatic competence of the Yemeni Non-Native Speakers of English (YNNSs) through examining their performance in the speech act of refusals. The study followed the qualitative comparative analytic approach. For the purpose of attaining the required data for this study, forty (YNNSs) and forty American Native Speakers (ANSs) of English were involved. The questionnaire used for collecting data from the participants was a written Discourse Completion Task (DCT), which was developed by Beebe et el. (1990), employed for collecting the data related to the use of refusal strategies by the two groups of participants in English. The data collected from DCT was analyzed by using a loading scheme adapted from Beebe et al. (1990). This study revealed that the Yemeni NNSs were not pragmatically competent enough in English. In spite of the similarity between the two groups in their use of refusal strategies, the differences between them were more apparent. The total number of strategies used by the American NSs was almost double those used by the Yemeni NNSs in all refusal situations. This study recommends that instructors should design contextualized, task-based, oral activities and integrating the intercultural aspects of language into ELT textbooks.
\end{abstract}

Keywords: pragmatic competence, EFL learners, Yemen

i Correspondence: email hamadakazme990@gmail.com 


\section{Introduction}

Teaching and learning the English language are crucial elements of the curricula at various levels of education in most of the countries around the world and in Yemen as well. It has become a necessary means of communication. Since the beginning of the new millenary, English has become an international language. The establishment and global extent of English have been developed by four foremost parts, particularly; the global expansion of the British Empire, the United States of America rise in political, economic, and power, the modern growth in data, technology, and information towards internationalization and globalization (House, 2006).

Carrying into consideration this consequence of the use of English as a system of universal language, teaching and learning are needed in the community. Though, it was considered by Crystal (2010) argues that in order to help students become communicatively competent in English, there is a need to move away from the 1960s theoretical framework that viewed language as a formal system (Structural Linguistics and Transformational Generative Grammar) and toward a more communicative perspective.

For this reason, researchers of different scientific developments, including discourse analysis, sociolinguistics, psycholinguistics, and ethnography of speaking tried to search the variety of communication and link language to extra-linguistic circumstances. This shift was encouraged by the scholars of pragmatics as a distinct field of research (Alcaraz, 1990).

Pragmatic ability performs a main position in the communicative competence to understand the capacity of communication and the contextual meaning. According to Mey (2006), the risk of errors raised among users beside various cultural and social frameworks is always carried by the intercultural contacts. Studying the pragmatic competence has illustrated that the growth of linguistic does not ensure the similarity of pragmatic improvement of Second Language SL learners (Bardovi-Harlig and Dornyei, 1998) regularly high-level scholars may miss understanding to communicate the expected purposes and courtesy values. Furthermore, grammatical competence and the socio-cultural rules should be acquired appropriately by SL learners Olshtain and Blum-Kulka (1985).

The capability to recognize the suitability of an utterance within a provided context and to take one possible form over another based on that knowledge is one of the most important professions correlated and needed with pragmatic competence (Kasper \& Rose, 2002). Therefore, it can be argued that the capacity to discriminate with various contexts in terms of their specifications of custom, politeness, etc., is an inseparable element of pragmatic knowledge.

Many studies in pragmatism within the framework of speech acts have been conducted. Speech acts can be considered as 'functions' of speech, like thanking, apologizing, refusing, complaining, inviting, and requesting. To produce speech acts and presumably speech acts, all languages have a universal system of themselves; even the pattern worked in a particular speech act is regarded by the impact of cross-cultural diversity on SL review and the scientific opportunities accessible in languages for speech act understanding. 


\section{Study Questions}

This study intends to answer to the following questions:

1) What are the refusal strategies used by the Yemeni NNSs of English and American NSs in negotiating refusals in English?

2) Are there significant differences between the sets of speakers?

\section{Review of Related Literature}

Leech (1983, p.34) argues "We cannot really understand the nature of language itself unless we understand pragmatics". Pragmatics is a fairly new linguistic discipline when comparing with phonology, morphology, and syntax. Scholars such as Wittgenstein (1953, in Bach, 2004, p.35) stated that the result of thoughts concerning the use and function of language in linguistic pragmatics has its basis in language comprehension. (Morris, 1938) it is initially located indoors of the philosophy of language but was transferred from this area to be correlated to sociolinguistics. The concept of pragmatics has not been a realized development and it included issues that could not be placed in another field of linguistics in the 1960s, (Leech, 1983, p.1). Consequently, in the 1970s language practice and setting gained more care and, pragmatics as a part of linguistics was recognized. Claim raised by Crystal (2010), that since pragmatics, meets among several different linguistic fields and includes various distinctive facts of language usage is not a comprehensible field of study. Thus, scholars point to determine it according to their concerns and study purposes. For instant, pragmatics has been defined separately concerning the authors' philosophical orientation and audience (Kasper \& Rose, 2001).

Levinson (1983) is one of the earliest researchers who spent most of his first chapter explaining this concept, trying to solve the problem of pragmatics notion. Nevertheless, rather than producing one distinct definition, several possible definitions were presented to pragmatics. He submitted many definitions but no one he performed is satisfying. His study also involved that it is not likely to conform to a definite perception of the notion of pragmatics. Particularly pragmatics seems to be a challenging notion to be defined; several scholars have attempted to give their explanations of this article like pragmatists, linguists, and applied linguists so that most of the definitions given are according to their perspectives.

To explain the notion of pragmatics Levinson (1983) stated that making a frame among grammar and pragmatics could be the introductory period. Levinson have been submitted two aspects of pragmatics. Aspect number one is that pragmatics has no correlation to do with language structure and only regarded with the usage of language. Second aspect in his contrast between competence and performance Chomsky (1965) proposed that pragmatics is particularly concerned with production methods of language practice.

Additionally, Leech (1983) defined pragmatics as the research of how sentence have meaning in context. Furthermore, several definitions of pragmatics concentrate on the use of context. A context-dependent definition suggested by Levinson (1983, p.21) "pragmatics is the study of the relations between a language and a context that are basic to an account of language understanding". Moreover, when determining pragmatics as the knowledge of people's 
understanding and creation of linguistic act in a context Kasper and Blum-Kulka (1993) in his declaration about the use of context in pragmatics. Besides, Mey (2001, p. 6) stated that "pragmatics studies the use of language in human communication as determined by the conditions of society".

Al Marrani and Suraih (2019) investigated the types of invitation strategies as produced by Yemeni EFL learners. The study involved 171 undergraduate students from Sana'a University. The DCT was used to collect the data. The results of the study showed that the Yemeni EFL learners preferred to be direct in the use of the speech act of invitation making, with highest frequency of imperative strategy followed by Yes/No questions strategy. In addition, the learners were aware that there is no problem with using direct invitations because they are acceptable in their culture. The study also found that the utterances translated from the mother tongue into the target language by Yemeni EFL learners without considering the distinctions between the two languages in sentence models and word order.

Taghizadeh (2017) conducted a study in the target language of Iranian learners of English with the aim of examining their pragmatic competence. Mixed-methods used in collected data.50 Iranian NNSs and 37 American NNs participated in this study. In addition, this study developed a new questionnaire to measure the knowledge of conversational implicatures and presuppositions of Farsi learners of English. The results indicated that the Iranian learners of English lack the knowledge of conversational implicatures and presuppositions in English.

Al-Eryani (2007) investigated the speech act of refusal made by the Yemeni EFL learners. The participants were 20 Yemeni Arabic NSs compared to 20 American NSs of English. The study used (DCT) to collect the data. The data were analyzed in terms of semantic formula series and were classified according to the refusal taxonomy by Beebe 1990. The results showed that crosscultural variation was evident in the frequency. The Yemeni NSs of Arabic tended to use "reasons" or "explanations" and were less direct in their refusals. American NSs English used "regret" and giving more direct refusals. The evidence of pragmatic competence of the target language was showed by The Yemeni learners of English.

The relevant studies to the topic of pragmatic competence, and pragmatic competence were very close to the present study, while this study differed in terms of the number of the participants, the strategies of directness, the level and type of strategies whereas most of the previous studies varied in between the level, the types, the number of the strategies used. Lastly, this study targeted the Yemeni graduates and most of the previous studies focused on undergraduate students.

\section{Materials and Methods}

In accordance with the comparative nature of this study, eighty participants were included and divided into two groups as follows:

- Forty Yemeni NNSs of English who graduated from English language departments, Faculties of Languages, Education and Arts, at Sana'a University. They aged between 22 and 34 years, four of them were working as supervisors, seven are in role in master's degree program, fifteen were working as English teachers distributed between private 
and public schools and the rest fourteen are unemployment. Only 9 participants of 40 were males while 31 participants were females.

- Forty English NSs from the United States of America who were enrolled in colleges and universities, especially Clover Park Technical College, Tacoma Community College in Washington State. They aged between 18 and 32 years. 27 of the participants were females while 13 participants were males.

\subsection{Instrument}

To collect the data for this study the researcher used the tool Discourse Completion Task in which is developed by Beebe et el. (1990), about the speech act of refusal. DCT is "written questionnaires including a number of brief situational descriptions, followed by a short dialogue with an empty slot for the speech act under study" (Kasper \& Dahl, 1991, p. 221). In recent years DCT has become the standard method of pragmatic knowledge evaluation for assessing knowledge of speech acts Kasper (2000). The employed DCT in this study presented twelve written situations in which American NSs and Yemeni NNSs of English use similar or different techniques while utilising the act of refuse. The twelve situations were categorized into four categories: three invitations, three requests, three suggestions and three offers those four types could only be answered by a refusal. Each situation type included one refusal to a person of higher status, one to a person of equal status, and one to a person of lower status to see how participants can recognise people's social positions while performing a speech act of refusal.

The participants were instructed to finish the task by writing down their answers to each case in DCT. Finally, the information gathered was coded according to the taxonomy of refusals amplified by Beebe et al. (1990).

\subsection{Data Collection Procedures}

This study included 80 participants, 40 Yemeni NNSs of English and 40 American NSs of English. The two groups were invited and to answer the DCT by writing down their answers to all the 12 statements. Participants were instructed to carefully read the introduction information supplied before each situation in order to recognise the type of every statement. The statements were an invitation, a request, an offer or a suggestion and the social status of interlocutors were higher, equal or lower. They were also instructed that the only way to provide an answer to any question by refusal. The participants in both groups were given half an hour to complete the DCT in English. DCT questionnaires of the Yemeni NNSs of English was administrated by the researcher in Moean district, Sana'a Yemen especially in Arkan modern schools, Noor Alketab school, Alqomaieah public school and Omer Ibnabulazeez school while the DCT questionnaires of American NSs of English were administrated by the researcher's wife in Washington State USA.

\subsection{Data Analysis Procedures}

Following the collection of pertinent data from 80 participants, this component included two sets of responses to similar situations (refusals) by two groups of respondents, 40 Yemeni NNSs and 40 American NSs, both in the same language (English). The data obtained was analysed using statistical techniques SPSS. To answer the study's first question, how do Yemeni NNSs differ 
from American NNSs when refusing in English, and to what extent do Yemeni NNSs approximate or break the pragmatic norms of refusing in English? A loading strategy adapted from Beebe et al. (1990), was used to examine the obtained data.

The classification of the refusal methods employed by the two groups of respondents according to the type of the refusal strategy contained in this study was performed using data content analysis; direct, indirect refusal strategies or adjuncts to refusals, based on a distribution system proposed by Beebe et al. (1990). Furthermore, the data acquired through the DCT was examined using an individualistic analysis of each response using the semantic formulas developed by Beebe et al. (1990). For instant, if a participant refused his friend's invitation to his house for lunch, saying "I'm sorry, I already have plans. Maybe next time.", this response was coded as: [direct refusal] [expression of regret] [excuse] [offer of alternative] (Beebe, Takahashi, \& Uliss-Weltz 1990, p.57). Then, for each case, the frequency of each formula used by all participants was numbered and sorted. Finally, the variations in strategies, directness, and social status between Yemeni NNSs and American NSs of English responses were counted and examined. The statistical tabulation and interpretation of the obtained data from the two groups of respondents in this study are shown in the section below.

\section{Results and Discussion}

In order to evaluate the Yemeni NNSs' pragmatic competence in English as the TL, the frequency of the used refusal strategies by them and by the American NSs were calculated and recorded in the following table.

Table 4.1: Frequency of Refusal Strategies Made by the Yemeni NNSs and American NSs

\begin{tabular}{|c|c|c|c|c|c|c|c|c|c|c|c|}
\hline \multirow{2}{*}{$\begin{array}{l}\text { Level of } \\
\text { Directness }\end{array}$} & \multirow{2}{*}{$\begin{array}{l}\text { Type } \\
\text { of } \\
\text { Strategy }\end{array}$} & \multicolumn{5}{|c|}{ Yemeni NNSs of English } & \multicolumn{5}{|c|}{ American NSs of English } \\
\hline & & $\begin{array}{c}\text { Higher } \\
\text { status }\end{array}$ & $\begin{array}{l}\text { Equal } \\
\text { status }\end{array}$ & $\begin{array}{l}\text { Lower } \\
\text { status } \\
\end{array}$ & \begin{tabular}{|c|}
$\begin{array}{c}\text { Total } \\
\text { per Str. }\end{array}$ \\
\end{tabular} & $\begin{array}{c}\text { Total per } \\
\text { Group } \\
\end{array}$ & $\begin{array}{c}\text { Higher } \\
\text { status }\end{array}$ & $\begin{array}{l}\text { Equal } \\
\text { status }\end{array}$ & $\begin{array}{l}\text { Lower } \\
\text { status }\end{array}$ & $\begin{array}{c}\text { Total } \\
\text { per Str. }\end{array}$ & \begin{tabular}{|c|} 
Total per \\
Group \\
\end{tabular} \\
\hline Direct & Direct Refusal & 72 & 66 & 58 & \begin{tabular}{|c|}
196 \\
$20.4 \%$ \\
\end{tabular} & \multirow{16}{*}{$\begin{array}{c}962 \\
36.08 \%\end{array}$} & 70 & 144 & 74 & $\begin{array}{c}288 \\
16.9 \% \\
\end{array}$ & \multirow{16}{*}{$\begin{array}{c}1704 \\
63.92 \%\end{array}$} \\
\hline \multirow{9}{*}{ Indirect } & Regret & 28 & 52 & 62 & \multirow{9}{*}{$\begin{array}{c}574 \\
59.7 \%\end{array}$} & & 46 & 64 & 66 & \multirow{9}{*}{$\begin{array}{c}1050 \\
61.6 \%\end{array}$} & \\
\hline & Wish & 4 & --- & 8 & & & 2 & 2 & 12 & & \\
\hline & Excuse, Reason & 52 & 92 & 98 & & & 120 & 150 & 154 & & \\
\hline & St. Alternative & 14 & 6 & 4 & & & 36 & 20 & 32 & & \\
\hline & Future acceptance & 10 & 2 & 4 & & & 20 & 6 & 10 & & \\
\hline & Set condition & 2 & 2 & 2 & & & 4 & 8 & 10 & & \\
\hline & $\begin{array}{l}\text { Attempt to } \\
\text { dissuade } \\
\text { interlocutor }\end{array}$ & 24 & 12 & 12 & & & 62 & 34 & 28 & & \\
\hline & Let off the hook & 36 & 2 & --- & & & 52 & 4 & 10 & & \\
\hline & Avoidance & 16 & 12 & 18 & & & 44 & 32 & 22 & & \\
\hline \multirow{4}{*}{ Adjuncts } & Positive opinion & 16 & 12 & 6 & \multirow{4}{*}{$\begin{array}{l}192 \\
20 \%\end{array}$} & & 10 & 4 & 12 & \multirow{4}{*}{$\begin{array}{c}366 \\
21.4 \%\end{array}$} & \\
\hline & Willingness & 6 & 8 & 12 & & & 30 & 18 & 30 & & \\
\hline & Gratitude & 38 & 64 & 30 & & & 88 & 90 & 72 & & \\
\hline & St. Empathy & --- & --- & --- & & & 8 & 4 & --- & & \\
\hline \multirow{2}{*}{$\begin{array}{l}\text { Total } \\
\%\end{array}$} & & 318 & 330 & 314 & 962 & & 592 & 580 & 532 & 1704 & \\
\hline & & $33.1 \%$ & $34.3 \%$ & $32.6 \%$ & $100 \%$ & & $34.7 \%$ & $34.1 \%$ & $31.2 \%$ & $100 \%$ & \\
\hline
\end{tabular}


The table above shows the cycle of refusal strategies used by the American NSs and the Yemeni NNSs. From the results given in Table 4.1 above, the remarkable gap between the two groups, in terms of the total number of strategies, can be noticed easily. Whereas the American NSs used a total of 1704 strategies (63.92\%), only 962 strategies (36.08) were used by the Yemeni NNSs in all refusal situations.

\subsection{Analysis of the Levels of Directness Demonstrated by the Two Groups}

By examining the data obtained from the respondents, it is found that the Yemeni NNSs and American NSs were similar, to some extent, in the level of direct refusals they made. According to the results displayed in Tables $4.2,4.4$ and 4.4 below, it is found that the total number of refusal strategies used by the two groups in the direct level were 196 and 288 respectively in which the $\mathrm{p}$ value between them, as in Table 4.4, was 0.032 lower than $0.05(\mathrm{P}<.05)$. As the $\mathrm{p}$-value is lower than 0.05 then it is reasonable to assume that there is no difference between the two groups' strategies used in the direct level. In this test if the computed significance value (P value) is either equal or lower than 0.05 , the critical value, then the difference between the frequencies is said to be insignificant in rejection of the assumed similarity between the two groups' responses. However, for the other types of refusal strategies, indirect and adjuncts, the two groups were found different. Whereas the American ENSs used 1050 indirect strategies and 366 adjuncts, Table 4.3, the Yemeni NNSs used 574 indirect strategies and 192 adjuncts, Table 4.2. According to $\mathrm{p}$-values in Table 4.4, it is found that the two groups were different in these two types of refusal strategies as the p-value for both groups in indirect strategies was 0.603 higher than $0.05(\mathrm{P}>.05)$ and in adjuncts it was 0.564 higher than 0.05 (P>.05).

Table 4.2: Strategies Frequency per Directness Level of the Yemeni NNSs

\begin{tabular}{|l|c|c|c|c|c|c|c|}
\hline \multirow{2}{*}{ Type of Strategy } & \multicolumn{3}{|c|}{ Social Status } & \multirow{2}{*}{ Total } & \multirow{2}{*}{ Percent } & \multirow{2}{*}{ Mean } & \multirow{2}{*}{ P. value } \\
\cline { 2 - 7 } & Higher & Equal & Lower & & & & \\
\hline Direct & 72 & 66 & 58 & $\mathbf{1 9 6}$ & 20.4 & 65.33 & $\mathbf{0 . 0 0 4}$ \\
\hline Indirect & 186 & 180 & 208 & $\mathbf{5 7 4}$ & 59.7 & 23.06 & $\mathbf{0 . 0 0 5}$ \\
\hline Adjuncts & 60 & 84 & 48 & $\mathbf{1 9 2}$ & 20.0 & 21.33 & $\mathbf{0 . 0 2 6}$ \\
\hline Total & 318 & 330 & 314 & $\mathbf{9 6 2}$ & 100.0 & 36.57 & $\mathbf{0 . 0 1 2}$ \\
\hline
\end{tabular}

Regarding directness level in making refusals, the Yemeni NNSs tended to be more direct with people of higher social status by using (72) direct refusal strategies in comparison with people of other status, Table 4.2 above. They seemed to show a kind of formality by refusing directly to people superior to them. For people of lower social status, on the other hand, they used the fewest number of direct strategies (58) among the three different statuses. Here, they preferred to appear more kind with this type of interlocutors as refusing their requests, offers or invitations might disappoint them. What supports this argument is the highest frequency of indirect refusal strategies (208) utilized with people of lower social status. The majority of the strategies (574) utilized by the Yemeni NNSs was for indirect refusals. For using adjuncts, the participants found themselves more free to use (84) extra modifications to protect the positive face of interlocutors with equal social status. They believed that there would be no harm of softening their refusals with more adjuncts. 
Ahmed Qasem H. Al-Khadhmi, Mirza M. B., Abdulla Ali Al-Eryani

PRAGMATIC COMPETENCE OF THE YEMENI EFL LEARNERS

Table 4.3: Strategies Frequency per Directness Level of American NSs

\begin{tabular}{|l|c|c|c|c|c|c|c|}
\hline \multirow{2}{*}{ Type of Strategy } & \multicolumn{3}{|c|}{ Social Status } & \multirow{2}{*}{ Total } & \multirow{2}{*}{ Percent } & \multirow{2}{*}{ Mean } & \multirow{2}{*}{ P. value } \\
\cline { 2 - 7 } & Higher & Equal & Lower & & & & \\
\hline Direct & 70 & 144 & 74 & $\mathbf{2 8 8}$ & 16.9 & 96.00 & $\mathbf{0 . 0 5 7}$ \\
\hline Indirect & 386 & 320 & 344 & $\mathbf{1 0 5 0}$ & 61.6 & 38.89 & $\mathbf{0 . 0 0 3}$ \\
\hline Adjuncts & 136 & 116 & 114 & $\mathbf{3 6 6}$ & 21.5 & 33.67 & $\mathbf{0 . 0 0 6}$ \\
\hline Total & 592 & 580 & 532 & $\mathbf{1 7 0 4}$ & 100.0 & 56.19 & $\mathbf{0 . 0 2 2}$ \\
\hline
\end{tabular}

For the American participants, the concept of directness appeared to be different to some extent, particularly with interlocutors of equal social status. As showed in Table 4.3 above, the direct refusal strategies used by the American NSs with people having equal social status (144) doubled the strategies used with those of higher and lower social status together, (70) and (74) respectively. They seemed to be more direct with their counterparts as rejecting counterparts' requests or offers is not a face-saving threatening act in such cases. In indirect refusal strategies, the American NSs were more conscious of their unexpected responses.

For the people of higher social status, they used the largest number of indirect refusal strategies to show higher degree of politeness. For the people of equal and lower social status, the American group showed a lower level of directness according to the frequency of strategies in Table 4.3 above. The lowest frequency of indirect strategies with interlocutors having equal social status matches the highest frequency of direct strategies of the same kind in terms of politeness as per the kind of social status. Regarding the use of adjuncts, the American NSs responses were balanced as the frequencies of the used refusal strategies for the three kinds of interlocutors were not so different.

According to the results presented in Tables 4.2, 4.3 and 4.4, the following aspects of differences between the Yemeni NNSs and American NSs in using refusal strategies can be discussed:

First, the difference between the two groups in direct refusals with equal status is clear according to the number of strategies used by each group, (144) by the Americans and only (66) by the Yemenis. This difference is almost attributed to cultural differences in considering politeness norms as the strategies for direct refusal do not require high linguistic competency from the side of the Yemeni NNSs of English. As for the other categories of social status, higher and lower, the two groups were similar to a large extent. For the people of higher social status, 70 and 72 strategies were used while for those of lower social status 74 and 58 strategies were used by the American NSs and the Yemeni NNSs, respectively as in Tables 4.2 and 4.3 above. In spite of the noticed differences between the two groups' responses regarding the equal social status, the overall computed significance value ( $P$ value) in the use of direct strategies was 0.032 lower than the critical value 0.05 , then the difference between the frequencies is said to be insignificant, Table 4.4.

Second, in the indirect level, the American ENSs were generally different from the Yemeni NNSs of English. Indirect refusal strategies refer to verbal messages that camouflage and hide speakers' true intentions in terms of their wants, needs, and goals in the discourse situation. They include statements of 'regret', 'wish', 'excuse', 'reason', 'explanation', etc. Whereas the American NSs of English used 386 for higher, 320 for equal and 344 strategies for lower social status, the 
Yemeni NNSs of English used only 186, 180 and 208 strategies for higher, equal and lower social status respectively. Although the two groups were similar in the sense that the highest frequency of the used strategies was for indirect, the number of strategies used by the American group was almost the double of those used by the Yemeni group. Such difference could be attributed to some linguistic hurdles. The Yemeni NNSs of English seemed to lack the necessary linguistic competency to enrich their responses with more indirect refusal strategies. In accordance with these statistical differences, the total computed significance value ( $P$ value) in indirect refusal strategies made by the two groups, as in Table 4.4 above, was 0.603 higher than the critical value 0.05 , then the difference is said to be significant.

Third, for the use of adjuncts, one more instance of variances between the two groups of participants existed. Adjuncts are kind refusal strategies which function as extra modifications to protect the interlocutor's positive face. They include statements of 'positive opinion', 'willingness', gratitude' and 'empathy'. While the American ENSs used 558 adjuncts, the Yemeni NNSs used 366 only, Tables 4.2 and 4.3 above. Accordingly, as in Table 4.4, the total computed significance value ( $P$ value) for the use of refusal adjuncts by the two groups was 0.564 higher than the critical value 0.05 , then the difference is said to be significant. It might be the effect of native cultural conventions or the insufficient linguistic competency that made the Yemeni group to be different from their American counterparts in the use of refusal adjuncts.

Forth, the two groups of respondents were found different in the overall computed significance value for all the kinds of refusal strategies as the P value was 0.400 higher than the critical value 0.05. Consequently, the difference between the American ENSs and the Yemeni NNSs of English in using refusal strategies is said to be generally significant.

\section{Conclusion}

From the analyses presented in sections 4.2 and its subsections 4.2.1, 4.2.2 and 4.2.3 above regarding the Yemeni NNSs' pragmatic competence, it can be concluded that they are not pragmatically competent enough in English. Their pragmatic ability in realizing and performing the speech act of refusal was not so high. By comparing their responses and the frequency of refusal strategies used by them with those made by the American NSs, a noticeable gap was observed, particularly in the use of indirect refusal strategies and adjuncts. In many cases they rarely used some refusal strategies and in some other cases they did not use any strategies such as in statements of 'gratitude' and 'regret'.

In spite of the few instances of similarity existed between the two groups of participants, the total number of the used strategies and the overall $\mathrm{P}$ value of strategies frequency proved that there was a sort of pragmatic failure from the side of the Yemeni NNSs in making refusals in the TL. However, this failure could be attributed to some interfering factors such as the influence of native culture or the possible negative effect of linguistic incompetency.

To sum up, due to the fact that the Yemeni NNSs have not been ever in the TL community, they were deprived from using and practicing English in its authentic contexts so as to improve their pragmatic competency. NNSs linguistic competency in the TL does not guarantee a corresponding pragmatic competency. 


\section{Conflict of Interest Statement}

The authors declare no conflicts of interests.

\section{About the Authors}

Ahmed Qasem H Al-Khadhmi is scholar student of PhD at School of literature and languages Swami Ramanand Teerth Marathwada University, Nanded, he is lecturer in private universities, Yemen, he has lectured as a visiting invited speaker internationally and has delivered numerous talks at international conferences and has conducted seminars with international audiences. He has published articles in journals.

Mirza M. B. is an associate professor \& head Dept. of English, Indira People's College (IDCO), Nanded, India. He has lectured as professor/invited speaker internationally and has delivered numerous talks at international conferences and has conducted seminars with international audiences. He has published articles in journals.

Abdullah Ali Al-Eryani is an assistant professor \& head Dept. of English, Thamar university education faculty, Thamar, Yemen. He has lectured as a visiting professor/invited speaker internationally and has delivered numerous talks at international conferences and has conducted seminars with international audiences.

\section{References}

Alcaraz, F. C., \& Wreszinski, W. F. (1990). The Heisenberg XXZ Hamiltonian with Dzyaloshinsky-Moriya interactions. Journal of statistical physics, 58(1-2),45-56.

Al-Eryani, A. A. (2007). Refusal strategies by Yemeni EFL learners. The Asian EFL Journal, 9(2), 19-34.

Bach, K. (2004). Pragmatics and the philosophy of language. In L. Horn \& G. Ward (Eds.), The Handbook of Pragmatics (pp.463-487). Oxford: Blackwell.

Bardovi-Harlig, K., \& Dörnyei, Z. (1997). Do language learners recognize pragmatic violations? Pragmatic versus grammatical awareness in instructed L2 learning. TESOL Quarterly, 32, 233262.

Beebe, L. M., Takahashi, T., \& Uliss-Weltz, R. (1990). Pragmatic Transfer in ESL Refusals. In Ghazanfari M., Bonyadi A., \& Malekzadeh S. (2012). Investigating cross-linguistic differences in refusal speech act among native Persian and English speakers. International Journal, Islamic Azad University.

Chomsky, N. (1965). Aspects of the Theory of Syntax. Cambridge, MA: MIT Press.

Crystal, D. (2010). The Cambridge Encyclopedia of Language, (3 ${ }^{\text {rd }}$ Edition). Cambridge: Cambridge University Press.

Crystal, D. (2010). Begat: The King James Bible and the English Language. Oxford University Press.

House, J. (2006). Text and Context in Translation. Journal of Pragmatics, 38(3), 323-337. 
Kasper, G. (2000). Data Collection in Pragmatics Research. In H. Spencer Oatey (Ed.), Culturally speaking. Managing rapport through talk across cultures (pp.316-341). London and New York: Continuum.

Kasper, G., \& Blum-Kulka, S. (Eds.) (1993). Interlanguage pragmatics. New York: Oxford University Press.

Kasper, G., \& Dahl, M. (1991). Research Methods in Interlanguage Pragmatics. Studies in Second Language Acquisition, 13(2),215-247.

Kasper, G., \& Rose, K. R. (2002). Pragmatic development in a second language. Michigan: Black well. Kasper, G., \& Rose, K. R. (2001). Pragmatics in language teaching. Cambridge: Cambridge University Press.

Leech, G. N. (1983). Principles of Pragmatics. New York: Longman.

Levinson, S. (1983). Pragmatics. Cambridge: Cambridge University Press.

Mey, J. (2001). Pragmatics, an Introduction. United Kingdom: Black well Publishing.

Mey, J. (2006). Pragmatic Acts. In Brown \& Keith (Eds.), Encyclopedia of Language and Linguistics (2nded.). Elsevier, Oxford.

Morris, C. H. (1938). Foundation of the theory of signs. In O. Neurath (Ed.), International encyclopedia of unified science, 1. Chicago: University of Chicago Press.

Olshtain, E. \& Blum-Kulka, S. (1985). Degree of Approximation: Nonnative reactions to native speech act behaviour. In S. M. Gass \& C. Madsen (Eds.), In put in second language acquisition (pp.303-325). New York, NY: Newbury House.

Taghizadeh, R. (2017). Pragmatic competence in the target language: a study of Iranian learners of English (Doctoral dissertation). University of Salford, Greater Manchester, England. 
Creative Commons licensing terms

Author(s) will retain the copyright of their published articles agreeing that a Creative Commons Attribution 4.0 International License (CC BY 4.0 ) terms will be applied to their work. Under the terms of this license, no permission is required from the author(s) or publisher for members of the community to copy, distribute, transmit or adapt the article content, providing a proper, prominent and unambiguous attribution to the authors in a manner that makes clear that the materials are being reused under permission of a Creative Commons License. Views, opinions and conclusions expressed in this research article are views, opinions and conclusions of the author(s). and European Journal of Literature, Language and Linguistics Studies shall not be responsible or answerable for any loss, damage or liability caused in relation to/arising out of conflicts of interest, copyright violations and inappropriate or inaccurate use of any kind content related or integrated into the research work. All the published works are meeting the Open Access Publishing requirements and can be freely accessed, shared, modified, distributed and used in educational, commercial and non-commercial purposes under a Creative Commons Attribution 4.0 International License (CC BY 4.0). 